\title{
CONSIDERAÇÕES SOBRE CUIDAdo PALIATIVO E TRABALHO HOSPITALAR: UMA ABORDAGEM PluRAL SOBRE O PROCESSO DE TRABALHO DE ENFERMAGEM $^{1}$
}

\author{
Miguel de Simoni ${ }^{2}$ e Mônica Loureiro dos Santos ${ }^{3}$ \\ Universidade Federal do Rio de Janeiro
}

\begin{abstract}
O objetivo deste artigo é apresentar o esforço de síntese dos autores sobre material de pesquisa em cuidados paliativos e bibliografia estudada. Inicialmente, apresentamos algumas considerações sobre cuidado paliativo em dois países estruturalmente distintos, Brasil e França. A discussão está centrada nas experiências de pesquisa dos autores em um serviço de AIDS no Brasil e em um serviço de Medicina Interna na França, que adotava a lógica dos cuidados paliativos e abrigava predominantemente pacientes com AIDS e câncer. Abordamos, em seguida, aspectos referidos à dor e à morte, considerando conceitos da Bioética e a dimensão relacional do cuidado em saúde. Os conceitos assinalados são os de justiça, autonomia, beneficência e não-maleficência. Concluímos, apresentando algumas possíveis contribuições da Ergonomia e da Psicodinâmica do Trabalho na área de Cuidados Paliativos, considerando especialmente a dimensão psicológica deste debate.
\end{abstract}

Descritores: Sofrimento. Cuidados paliativos. Hospitais. Ergonomia. Saúde mental.

1 Este artigo é baseado em um capítulo da tese de doutorado, defendida por Mônica Loureiro dos Santos, no Programa de Engenharia de Produção da COPPE/UFRJ, em fevereiro de 2001; Orientador: Miguel de Simoni. Apoio do Programa Alfa/Fanal-Sup, financiado pela Comunidade Econômica Européia, no período de altubro de 1999 a janeiro de 2000.

2 Endereço para correspondência: R. Urucum, 553, Bangu - 21.820-390 - Rio de Janeiro, RJ.

3 Psicóloga, Professora Assistente, FM/NESC/UFRJ. Endereço para correspondência: R. Jean Paul Sartre, 66/302, Barra da Tijuca - 22.793-260 - Rio de Janeiro, RJ. Endereço eletrônico: monical@nesc.ufrj.br.

Psicologia USP, 2003, 14(2), 169-194 
uidados paliativos é um termo adotado na modernidade para o cuidado
em fim de vida. É um termo vinculado à morte ritualizada nos hospitais dos grandes centros urbanos, embora não esteja necessariamente associada ao fim de vida medicalizado.

Uma das grandes dificuldades ao tratar o tema é a abordagem da desocultação da morte associada a doenças imunológicas, como a AIDS, e a representação social sobre a dor.

Não estando associado a uma doença específica, o cuidado paliativo é tradicionalmente objeto de reflexão, principalmente na área médica da oncologia. A AIDS, ao transformar-se em doença tratável por medicamentos e psicoterapias, pode estar associada ao cuidado paliativo de modo muito tênue.

Tecnicamente, o cuidado paliativo está associado ao cuidado da dor, com especializações médicas - especialmente na França - e de outras áreas da saúde (informação verbal, equipe do Ambulatório da Dor, no hospital estudado no Brasil, 2000), incluindo a administração de analgésicos. Segundo divulgação recente em meios não-acadêmicos, no Brasil existe preconceito entre enfermeiros - também extensivo aos médicos - acerca da analgesia, associada ao vício com a medicação, segundo pesquisas realizadas em São Paulo (Vergara, 2001).

Em tempos de consumo como solução oferecida para a angústia que faz parte da vida, a morte, quanto mais longe estiver do espectro de possibilidades imediatas, mais se apresenta como um espetáculo inúmeras vezes repetido, seja nos programas infantis, seja no noticiário diário dos adultos. No entanto, como tema de conversa, é sempre desagradável, e sempre que possível, expurgado como um invasor indesejado.

Para isto, afinal, existem instituições adequadas como os hospitais e asilos para idosos. E existem, também, pessoas treinadas para isto, as enfermeiras. Tive a oportunidade de conviver durante a pesquisa de doutorado (entre 1997 e 2000), com pessoas deste campo de atuação em dois hospitais universitários, um no Rio de Janeiro e outro em Paris. Tenho como objetivo assinalar uma problemática neste percurso: o sofrimento psíquico das equipes de enfermagem, situadas no trabalho de cuidados paliativos. 
Considerações sobre Cuidado Paliativo e Trabalho Hospitalar...

O exercício solitário de perscrutar os movimentos de alguém que está em coma ou impossibilitado de interação pela palavra pode ser realizado pela enfermagem no período da administração dos cuidados (banhos, medicação etc.). No entanto, saber que alguém oacompanha com o olhar pela enfermaria diminui o sentimento de solidão do paciente (Observações do trabalho e entrevista com enfermeiras em ala de pacientes graves, França, 1999).

Este vai-e-vem entre o olhar de quem cuida e o de quem é cuidado pode ser uma metáfora do sentimento partilhado pelos membros da equipe de enfermagem, nos últimos momentos de vida dos pacientes, que poderão estar nesta condição, ou de seus familiares, o que em alguns casos pode ser até mais doloroso (Discussão em grupo com pessoal de enfermagem, Brasil, 2000; Loureiro dos Santos, 2001).

A solidão em que se encontram as enfermeiras, auxiliares e técnicas de enfermagem no seu trabalho nos cuidados em fim de vida não é medida, apenas, pela quantidade de pessoas da equipe envolvida com a situação, mas avaliada, também, pela qualidade do fim de vida daquela pessoa. Morrer acompanhado pela família assegura, de certa forma, que uma determinada sociedade cultiva este valor como primordial. No entanto, assim como o paciente morrer sozinho pode ser um problema para a enfermagem, morrer acompanhado também pode tornar-se um problema.

Embora a organização do trabalho de enfermagem apresente diferenças no Brasil e na França (quanto à divisão das tarefas, tipo de qualificação exigida, condições de trabalho e salário, por exemplo), determinados sentimentos estão presentes em ambos os países. Podemos atribui-los à natureza do trabalho?

Relacionado ao tema da solidão das enfermeiras (ver, por exemplo, revisão da literatura francesa realizada por Damasceno, 1998), o medo da loucura e do adoecimento físico perpassa a vida profissional destas pessoas, principalmente no Brasil. Como conciliar a vida fora do hospital, se os problemas dos pacientes continuam mobilizando psiquicamente a enfermeira - a auxiliar e a técnica - em espaços fora do trabalho? (Discussões em grupo com pessoal de enfermagem, Brasil, 1998; Loureiro dos Santos, 2001). 
É difícil encontrar enfermeiras que não tenham uma religião declarada, no caso do Brasil, ou que não partilhem de uma religiosidade transmuta$\mathrm{da}$, como entre os franceses.

No entanto, as relações com as igrejas oficiais ou não, podem configurar-se por uma convivência obrigatória e desconfortável, considerando que as manifestações que rondam o adoecimento e a morte podem ser ruidosas e pouco adequadas ao ambiente asséptico e normativo do hospital (Observação do trabalho em enfermaria no Brasil, 1998; Loureiro dos Santos, 2001).

O reconhecimento de inserções culturais diferenciadas em uma mesma sociedade é uma construção, e supõe a relativização de seus próprios valores. Como se dá o encontro entre culturas e valores diferentes, no cenário do hospital, em torno dos temas da dor e da morte? As sociedades ditas "primitivas" continuam se relacionando com seus mortos e ritualizando uma passagem para outra fase da vida, o que nem sempre é possível nas sociedades ocidentais contemporâneas.

Nos dois serviços observados, havia apoio psicológico aos pacientes internados e às equipes de enfermagem. No Brasil, quanto a estas últimas, observou-se uma maior informalidade, além do recurso tradicional de atendimento individual no próprio hospital.

A proximidade de classe da enfermagem com a clientela atendida na assistência de saúde pública a situa, por vezes, como ator antagônico ao papel exercido pelo médico. Mas não se trata, apenas, de um antagonismo de classe, pois apresentam lógicas profissionais diferentes. À identificação de classe, justapõem-se outras - etnia, gênero, preferência sexual etc. - no que diz respeito à relação da enfermagem com a clientela atendida. Esta clientela, não raramente, irá se constituir do vizinho, colega ou até mesmo parentes.

A sensação de "perder vidas" será distinta se a perda for de algum parente ou pessoa próxima. Perde-se, assim, com o investimento afetivo, uma parte de si. Com o tempo, se for bem elaborado o luto, torna-se a lembrança de alguém querido (Freud, 1917/1974). Os sentimentos que alimentamos em relação às pessoas próximas podem ser ambivalentes, e quando se anuncia 
Considerações sobre Cuidado Paliativo e Trabalho Hospitalar...

uma morte próxima, isto fica muito evidente. Raiva e culpa não são sentimentos incomuns.

Para a enfermagem, assim como para o senso comum, existem diferenças em cada tipo de morte (ver, por exemplo, Bulhões, 1994): se é a morte de uma criança ou de um adulto; se é uma morte súbita ou anunciada; qual o tipo de sofrimento antecedente.

Nem sempre a identificação positiva com a clientela tem lugar, e ocorrem complexos mecanismos psicológicos de defesa que podem ceder espaço a condutas nãoéticas. Estes fenômenos podem ocorrer com qualquer membro da equipe, inclusive o médico. Ao ultrapassar o limiar entre a sanidade e a loucura, as componentes da equipe de enfermagem podem ser protagonistas de atitudes consideradas criminosas. Eventos deste tipo, já denunciados pela mídia televisiva e escrita, concorrem para uma imagem negativa do poder da enfermagem. Como isto é vivido pelas equipes em cuidados paliativos?

Os membros da equipe, que optam por outro tipo de defesa frente à organização do trabalho, podem vivenciar de forma suplementar o sofrimento de cuidarem dos pacientes mais graves com maior frequiência. Descompensações somáticas e psíquicas são relatadas a respeito deste tipo de exigência ética em outras instituições, que não os hospitais estudados.

Sem o trabalho oferecido nas modalidades presentes nas sociedades contemporâneas, a inserção social e afetiva para alguns pacientes torna-se problemática. A noção de se tornarem um "fardo" não é incomum. A hospitalização em fim de vida atende muitas vezes à impossibilidade de as famílias manterem, por tempo indeterminado, um doente em casa enquanto trabalham, principalmente quando a autonomia e a independência motoras do paciente estão seriamente comprometidas ou quando não conseguem suportar assistir ao sofrimento de uma pessoa querida. Além disso, estão presentes as dúvidas éticas surgidas nestas mesmas sociedades, com a intensificação da tecnologia médica que permite prolongar uma certa "qualidade" de vida.

Para auxiliares e técnicas de enfermagem, assim como para a enfermeira, a profissionalização emuma organização em transformação, como é a assistência em saúde pública em tempos de globalização e precarização do 
trabalho, é um desafio. Como não se tornar um "robô" ou um "trem"? Estas são expressões utilizadas no Brasil pelo pessoal de enfermagem em referência à impessoalidade na convivência entre colegas e pacientes, aludindo a comportamento adotado como defesa contra os ritmos e cargas excessivas de trabalho.

Quando a morte é medicalizada, e ela o é cada vez com mais freqüência, ao menos nos centros urbanos, seu significado tende a ser desapropriado pelo discurso médico (Illich, 1975), que pode ser pronunciado por qualquer ator da área da saúde.

No Brasil, a reflexão sobre o cuidado paliativo pode ser favorecida, considerando que a introdução da ideologia individualista é muito recente entre nós. Nossos pequenos avanços no plano político, no entanto, dificultam a regulação social por meio da noção de cidadania.

A introdução de políticas de humanização dos hospitais brasileiros encontra resistências de natureza diversa daquelas encontradas nos países mais antigos. Principalmente a psicologia e a filosofia, assim como a arte, vêm sendo aliados importantes deste movimento que começa a ter visibilidade (ver, por exemplo, experiência sistematizada por Masetti,1999).

\section{Discussão sobre o termo "cuidado paliativo"}

Desta forma, definir o termo "cuidados paliativos" é uma tarefa extremamente complexa e desafiadora, considerando sua operacionalidade no que diz respeito à delimitação de um campo de atuação das ciências da saúde, envolvendo conceitos e sua articulação com formulações das ciências humanas: psicologia, filosofia, antropologia e história. Estes últimos buscam inserir a discussão do sentido e da narrativa acerca deste momento da vida humana tão enigmátic o, que é a morte.

A origem do termo situa-se em uma discussão da prática médica acerca do lidar com pacientes ditos terminais. Desta forma, o cuidado paliativo distingue-se do curativo pela noção médica de paciente "terminal" ou "fora 
de possibilidades terapêuticas". Qual a repercussão para uma pessoa que está em tratamento ouvir de seu médico que tem três meses, um ano ou dois a mais para viver?

A restrição do cuidado paliativo ao espaço medicalizado e científico mostrou-se, no entanto, insuficiente, e cada vez mais, nos países de industrialização avançada e em países intermediários como o nosso, a amplitude de recursos para lidar com a morte "anunciada" revela-se de forma mais ou menos limitada, considerando a disponibilidade dos dispositivos culturais. Não se trata, neste momento, da discussão sobre a oferta de tecnologia médica, mas sim dos recursos que as sociedades dispõem para ritualizar e dar sentido à vida e à morte.

Nesta perspectiva, definimos o cuidado paliativo como um campo científico e não-cie ntífico ao mesmo tempo, onde pessoas se organizam para lidar com suas próprias dificuldades e, também, das outras pessoas, acerca de uma transição enigmática para a ciência, a morte. $\mathrm{O}$ cuidado paliativo implica, principalmente, na relação entre as pessoas que cuidam e as que são cuidadas, sendo as intervenções técnicas secundárias à relação que se estabelece entre equipe de cuidados e pacientes. Em alguns casos, o campo de atuação profissional que inclui o cuidado paliativo mantém uma convivência ambivalente com as religiões, em sua forma mais ampla, para as quais a morte é certamente uma passagem para outra vida.

As definições de cuidado paliativo da Organização Mundial da Saúde (OMS) estão calcadas no modelo de tratamento do câncer, embora possam ser aplicadas a outros tipos de doença. Apresento uma das definições em seguida:

Cuidado paliativo é uma abordagem que aumenta a qualidade de vida de pacientes e suas famílias que enfrentam problemas associados com doenças que ameaçama vida, através de prevenção e alívio do sofrimento, provendo identificação precoce e avaliação exemplar, além de tratamento da dor e outros distúrbios de natureza físi- 
ca, psicossocial e espiritual. (World Health Organization [WHO], n.d., tradução livre dos autores) ${ }^{4}$

Esta definição de cuidado paliativo é universalista, apresentando uma noção de fim de vida como um processo natural para todos os seres humanos.

Os cuidados paliativos são preconizados por outros organismos internacionais, como a United Nations Educational, Scientific and Cultural Organization (UNESCO) $)^{5}$, implicando na estruturação de uma rede de atenção à saúde que é incipiente em nosso país, especialmente para as classes menos favorecidas. Mesmo para as classes médias, que dispõem de planos de saúde privados, muitas vezes os cuidados paliativos não estão previstos.

A problemática diferenciada nos países de economia central e nos países pobres é apontada pela OMS. Nestes últimos, encontra-se uma mescla de situações, ou seja, a mortalidade tanto por doenças infecciosas quanto por doenças crônicas. Além disso, a maior parte dos países não chegou a ser beneficiada por políticas de bemestar social.

Para a OMS (World Health Organization Western Pacific Region, n.d.), o alívio da dor, a redução do sofrimento e a oferta de cuidado paliativo para aqueles que não podem ser curados, até o momento, acham-se entre as principais prioridades para a ação internacional em saúde. Como já está sendo realizado na França há várias décadas, o relatório amplia o escopo de participação para além da figura do médico, dos serviços médicos ou sociais.

A AIDS é uma doença controversa para a qual não se vislumbra cura, segundo vários autores, e para a qual continua sendo investida toda sorte de pesquisas. Programas de combate à mortalidade provocada pela doença, em

4 "Palliative care is an approach that improves the quality of life of patients and their families facing the problem associated with life-threatening illness, through the prevention and relief of suffering by means of early identification and impeccable assessment and treatment of pain and other problems, physical, psychosocial and spiritual."

5 Ver, por exemplo, De Beir (1994) e Di Mola (1994). 
alguns países como o Brasil, foram avaliados como bem sucedidos a partir do aumento dos investimentos em drogas retro-virais.

Ao contrário da tuberculose e do câncer, que podiam acometer qualquer pessoa indiscriminadamente, a AIDS foi, desde os seus primórdios, associada a grupos de risco previamente estigmatizados: homossexuais, prostitutas, drogados. É, portanto, uma doença relacionada à transgressão, especialmente à sexualidade, mesmo que atualmente seja consenso que não há grupos populacionais imunes a priori à contaminação. Em algumas regiões do planeta, a epidemia da AIDS atinge mais intensamente as mulheres, sendo que na África sub-saariana predomina a transmissão heterossexual (Coordenação Nacional de DST e AIDS, n.d.). 6

Com a descoberta da cura da tuberculose, outras doenças irão ocupar o lugar central no imaginário social sobre a impotência do humano frente aos limites impostos pela natureza ou por suas próprias invenções (radiação, processos tecnológicos etc.). A morte anunciada será, então, associada a doenças crônicas como o câncer. Sontag (1984) trouxe algumas imagens geradas, seja no campo da ciência seja no da arte, acerca do que significa adoecer por câncer, comparando-as com as imagens a respeito de outras doenças.

A tuberculose e o câncer (como a sífilis) têm sido usados para exprimir não só grosseiras fantasias sobre contaminação, mas também complexos sentimentos em relação à força, à f raqueza e à energia. Por mais de um século e meio, a tuberculose

6 "As the HIV/ AIDS epidemics spread with more intensity among women in some areas, the transmission of HIV from mothers to newborns and infants is becoming increasingly frequent in Latin America and the Caribbean. (....) In general these rates are lower than those observed in other regions of the world where heterosexual transmission of HIV predominates - for example in sub-Saharan Africa - and they do not appear to be dramatically increasing over time. (Como a epidemia de HIV/ AIDS atinge com mais intensidade as mulheres em algumas áreas, a transmissão de HIV de mães para recém-nascidos está tornando-se crescentemente frequente na América Latina e no Caribe. (...) Em geral estas taxas são menores do que as observadas em outras regiões do mundo onde a transmissão heterossexual do HIV predomina - por exemplo na África sub-saariana - e elas não parecem estar crescendo de forma dramática no tempo).” (Tradução livre dos autores) 
produziu um equivalente metafórico de delicadeza, sensibilidade, tristeza e fraqueza, enquanto tudo que parecia cruel, implacável e predatório podia ser assemelhado ao câncer. (Sontag, 1984)

Embora não seja uma doença contagiosa como a tuberculose, a metáfora do contágio é pertinente, especialmente quando os índices de cura eram irrelevantes. No alvorecer do ano 2000, pode-se talvez pensar em uma mudança na representação da doença, pelo menos nos países industrializados. No Brasil, Schulze (1995) estuda as representações sociais de portadores de câncer e assinala que um dos aspectos que poderiam caracterizar os pacientes de classes sociais baixas no país é o medo da dor. Outras alternativas à morfina podem ser pensadas como o recurso à acupuntura, estudada no Rio de Janeiro por Cosendey (1999), no quadro das medicinas alternativas.

O Brasil é um dos países que recebem do exterior uma das menores cotas de morfina para consumo de pacientes terminais de câncer e, consequentemente, nossos médicos que trabalham em atendimento ambulatorial não podem prescrever, mesmo que queiram, as dosagens necessárias e corretas para o controle da dor como foi proposto pelo Programa da Organização Mundial de Saúde (OMS). (Ver Report of WHO Committee, 1990, citado por Schulze, 1995, p. 276)

Sendo uma doença associada ao estilo de vida adotado nos países de economia central, o indivíduo é o foco da prevenção do câncer: álcool, tabaco, sedentarismo são alguns dos problemas levantados como causas da doença. No entanto, os componentes ambientais, pouco mencionados, porém, presentes em diversos processos de trabalho ou como resultado de negligência/ignorância acerca dos poluentes ambientais, são apresentados como fatores importantes no aumento da incidência da doença (Mendes, 1995). Aí, também, podem ser apontadas diferenças entre países ricos e os de industrialização recente. Nestes últimos, processos de trabalho e tecnologias considerados perigosos e inadequados à saúde são transferidos sem qualquer crítica, agravando os problemas não resolvidos de saúde destas populações. Por exemplo, a discussão sobre o banimento do amianto no Brasil (Informação verbal, Vanda D’Acri, 1999). 
Das diferenças psicológicas às diferenças entre as classes sociais nos modos de vivenciar o fim de vida, pelos pacientes, familiares e profissionais de saúde, os cuidados paliativos são uma alternativa contemporânea à ritualização da morte, por um lado, e ao prolongamento da vida com qualidade, por outro.

Apresentarei uma breve revisão de algumas experiências que foram realizadas na França a respeito dos cuidados paliativos.

Richard (1996) analisa um serviço de medicina interna, o mesmo serviço estudado por nós. Na França, o movimento dos cuidados paliativos e as primeiras tentativas de refletir sobre o problema encontram um ambiente favorável, considerando as reflexões fora do meio médico, com Ariès (1977), Morin (1970/1997) e Thomas (1988, citado por Richard, 1996).

Os problemas apontados pelas supervis oras concernem, principalme nte, à dimensão relacional com pacientes e familiares, à formação e à ausência de meios materiais. A autora considera que as trocas e comunicações propiciadas nos grupos apresentaram um resultado favorável, no sentido de desvendar as resistências à prática dos cuidados paliativos e à melhoria das condições de fim de vida no hospital.

Já a intervenção ergonômica (Raso, 1996) foi realizada no mesmo serviço, principalmente junto às enfermeiras e auxiliares (infirmières e aidesoignantes). Os principais resultados desta intervenção, além de contribuir para maior democratização dos espaços de trabalho, foi a criação de grupos de estudo para o financiamento de meios de trabalho que facilitassem o desenvolvimento da atividade das enferme iras e auxiliares.

Mallet (1995) contextualiza, igualmente, o surgimento do movimento dos cuidados paliativos na França, assinalando uma ruptura para a medicina curativa que não se vê mais tão potente frente ao sofrimento e à morte, a despeito dos avanços tecnológicos.

O tempo dos cuidados paliativos passa a ser um tempo de prestar atenção à qualidade de vida, à vida interior e às relações. Deste tempo falam a psicanálise, a filosofia, a antropologia e a religião. É um tempo de vivenciar 
emoções intensas, de fazer (ou escutar) revelações e conceder (ou receber) o perdão do próximo. Depressão, raiva e tristeza podem ser vivenciadas junto à esperança.

O cuidado paliativo, segundo o autor, pode ser o alívio da dor, porém, principalmente, a atividade de escuta. Os cuidados consigo (alimentar-se, pentear-se, banhar-se etc.), administrados usualmente pela enfermagem aos pacientes dependentes, são complementados por saídas do hospital e passeios pelos jardins com os menos dependentes. $\mathrm{O}$ trabalho em equipe torna-se quase um imperativo, pois a enfermeira, a fisioterapeuta e a psicóloga passam a ser referências destes pacientes.

Problematizando a convivência entre lógica curativa e lógica paliativa, o autor não as vê como opostas, mas como pólos que podem ser priorizados em um momento ou outro. Esta é, portanto, uma reflexão ética em que o autor aponta a relação com a lei, no momento em que as equipes assistem a mortes freqüentes, podendo considerar a eutanásia uma solução para o sofrimento que não podem suportar.

\section{Dor, morte e bioética}

O movimento que procura imprimir o debate em torno das questões éticas na área da saúde é dominado, no Brasil, pela Bioética, o que não quer dizer que seja hegemônico. Não temos ainda, como na França, um movimento social de cuidados paliativos.

Neste último país, questionamse as formas de vivenciar a dor física que se afastam de um ideal religioso, ou seja, questiona-se a necessidade de vivenciar a dor como forma de expiação ou salvação. Tematizar a morte, não por morbidez mas por aceitá-la como parte da vida, tem sido mais facilitado por movimentos sociais, nos quais associações de cuidados paliativos apresentam voluntários para acompanhar pacientes fora de recursos atuais para cura. 


\section{Considerações sobre Cuidado Paliativo e Trabalho Hospitalar...}

Do ponto de vista psíquico, a representação sobre a dor pode agravar um quadro patológico. Por outro lado, diversos autores assinalam as diferenças segundo as classes sociais nas vivências acerca do corpo (Boltanski, 1984; Dejours, 1987), incluindo a questão da dor e da doença. A ausência ou escassez de opções levaria as classes mais pobres a negar ou minimizar a dor para continuar trabalhando.

Ao comparar os enterros civis e os católicos, Lalouette (1995), a partir de um ponto de vista historiográfico, assinala elementos abandonados e elementos novos encontrados nos primeiros em relação aos últimos. $\mathrm{O}$ que nos interessa demarcar com isto é que, mesmo sem uma crença religiosa, os livres pensadores na França reinventaram um rito funerário, aproveitando elementos da religiosidade dominante, a católica, acrescentando outras imagens e gestos como gritar "Viva a República!" no momento da despedida final.

A expressão nas lápides da idéia de imortalidade através da memória social seria o equivalente a um rito sagrado, embora neste ideário esteja ausente qualquer crença na alma ou na sua imortalidade efetiva. A autora apresenta algumas taxas como a de que os enterros civis correspondem a um quarto do conjunto dos óbitos na França, atualmente, retornando a índices do início do século. No entanto, assinala que o sentido destes enterros mudou, neste último século, com o engajamento coletivo e militante em uma busca individual e satisfatória do sentido da morte.

Oficialmente, no nosso país, a Igreja católica mantém locais de despedida aos mortos, como capelas nos hospitais. Cada vez menos minoritários, os cultos evangélicos se realizam no acompanhamento de pacientes em situação terminal. Outros cultos, como o dos espíritas kardecistas também oferecem, no Brasil, apoio espiritual nos hospitais.

Pela riqueza dos rituais indígenas e africanos no momento da morte são eles objeto de diversos estudos no campo da antropologia. Não é o objetivo deste trabalho apresentá-los, no entanto, considero importante assinalar que outros referenciais culturais que usualmente não se encontram no espaço científico do hospital, podem ser consultados como acervo de memória de 
outros componentes deste país, além dos colonizadores ou imigrantes brancos católicos (ver, por exemplo, o acervo de Antropologia Social do Museu Nacional, UFRJ).

Discutindo a relação entre morte e capitalismo nas sociedades ocidentais, Rodrigues (1983) analisa tendências às quais o engajamento coletivo analisado por Lalouette (1995) tenta resistir:

De fato, após os funerais, o esquecimento de que são vítimas os mortos faz deles fracos consumidores: as visitas às sepulturas vão se tornando cada vez mais esparsas e o consumo de que os mortos são responsáveis vai diminuindo com o tempo. É que este próprio esquecimento é condição de funcionamento do sistema: há uma incompatibilidade entre os valores da economia industrial e a aceitação da morte. A morte nega a idéia de acumulação de bens, a qual diante dela deixa de ter sentido. A morte questiona radicalmente as ideologias da eficácia e da competência e ridiculariza a competição social. Quebra radicalmente a linearidade do tempo (...) verdade insuportável para um sistema que quer que o tempo seja linear e adverte que "tempo é dinheiro". (Rodrigues, 1983, p. 284)

Em nosso país, podemos identificar, mais recentemente, elementos no cenário político e cultural que podem favorecer esta reflexão.

Situações extremas como o desaparecimento de pessoas durante disputas políticas - sem a localização dos corpos pelos familiares - podem levar a morte para o lugar do indizível (ver, por exemplo, Eloysa, 1987). Com o processo de democratização no país, este tema tem sido abordado, com mais frequiência, na mídia escrita e televisiva.

Também começam a surgir no cenário das artes algumas montagens em teatro sobre o tema, como a recente encenação, no Rio de Janeiro, de um texto europeu sobre o adoecimento por câncer de uma professora universitária e suas vivências (A Jornada de Um Poema, encenada em 2000).

Assim, variam as formas de morrer de acordo com os contextos políticos e sociais. $\mathrm{O}$ aumento da violência colabora para a banalização da morte e não para reflexões acerca do seu sentido.

O problema da dor e da morte são extremamente complexos nas sociedades ocidentais e a discussão em torno do lugar cultural de ambos permeia 
Considerações sobre Cuidado Paliativo e Trabalho Hospitalar...

as contradições e os dilemas vividos pelos profissionais de saúde que trabalham em serviços hospitalares.

No Brasil, estas discussões têm um lugar teórico privilegiado no ca mpo da Bioética ${ }^{7}$. É um campo que tem se ocupado dos dilemas morais implicados no cuidado aos doentes pelos profissionais de saúde, dentre outras questões. Pessini e Barchifontaine (1991) apresentam os principais conceitos deste campo de estudos: justiça, autonomia, beneficência e não-maleficência, sendo o conceito de justiça preponderante sobre o de autonomia.

Sobre o conceito de justiça, Fortes (1999) assinala suas mú ltiplas e opostas interpretações. Há, no entanto, certo consenso em considerá-lo como o equivalente de eqüidade, ou seja, considerar o bemestar de cada um em um contexto que favoreça o aumento de oportunidades para todos.

O autor analisa a escassez de rec ursos no setor público de saúde e a importância de se considerar este critério na escolha de pesquisas que produzam benefício para a coletividade. A avaliação da utilidade social, porém, é um assunto complexo na medida em que grupos minoritários podem não ser, ou se sentir, contemplados.

Sobre o conceito de autonomia, Schramm (1999) distingue-a em seu sentido ontológico e no sentido moral, voltando suas análises para esta última. A autonomia estaria, então, na capacidade de autodeterminação, opondo-se à heteronomia. $\mathrm{O}$ binômio autonomia/heteronomia seria oposto, por sua vez, à anomia no sentido durkheimiano.

Para Kant (citado por Schramm, 1999, p. 17), “(...) é a propriedade da vontade que se dá uma lei por si mesma, independentemente de qualquer propriedade dos objetos do querer". Para este filósofo, deve-se respeitar a autonomia dos outros e tratar a humanidade não somente como meio, mas

7 "Bioética é um neologismo derivado das palavras gregas bios (vida) e ethike (ética). Pode-se defini -la como sendo o estudo sistemático das dimensões morais - incluindo visão, decisão, conduta e normas morais - das ciências da vida e do cuidado da saúde, utilizando uma variedade de metodologias éticas num contexto interdisciplinar" (Encyclopedia of bioethics, 2nd ed., Vol. 1, citado por Pessini \& Barchifontaine, 1991). 
também como fim. Na ética moderna, a autonomia é universalizável, sendo considerados autônomos por outros autores em Bioética, até mesmo os pacientes psiquiátricos.

Considerando a dificuldade de se exercer a autonomia, Schramm propõe trabalhar com a dialética autonomia/heteronomia, considerando o valor do indivíduo em cada sociedade. Por fim, assinala o debate sobre a existência de uma ética dominante em nossa sociedade, em contraponto a uma pluralidade de comunidades morais.

O contexto cultural onde está inserido este sujeito é um fator importante a ser considerado, por exemplo, se é uma sociedade na qual predomina o protestantismo ou se são sociedades mais comunitárias. O Brasil, analisado dentre outros por Freyre (1977), apresenta características de sociedades comunitárias, com sua profusão de festas sagradas e profanas. O Quarup, de Callado (1984), apresenta um dos rituais mais importantes para os índios e a cultura brasileiros.

A relação desses conceitos com os de beneficência e não-maleficência são apontados por Pessini e Barchifontaine (1991), na discussão sobre a eutanásia:

Não estamos obrigados a fazer o bem a uma pess oa contra sua vontade, porém, não devemos fazer o mal, ainda que ela se oponha a isso. A justiça é inseparável da não-maleficência, da mesma maneira que a autonomia o é da beneficência (Pessini \& Barchifontaine, 1991, p. 355).

Algumas questões que estão, a nosso ver, vinculadas ao tema da saúde mental das trabalhadoras de enfermagem no Brasil são: Como se dão as decisões éticas? Quais os atores implicados e que repercussões podem apresentar para a organização do trabalho em hospitais?

Quanto ao controle da dor, por exemplo, podem estar relacionados valores religiosos como os apontados por Pessini e Barchifontaine (1991). Para estes autores, o significado da dor para um católico é a participação na Paixão de Cristo. A discussão sobre o uso dos analgésicos tem, como um dos critérios, a perda ou não de consciência, nos momentos que precedem a 
Considerações sobre Cuidado Paliativo e Trabalho Hospitalar...

morte. Qual a implicação disto para o paciente e o profissional de saúde que dele está cuidando?

Segundo os autores acima, para além do uso técnico dos analgé sicos, o grau de consciência em que o paciente se encontrar poderá determinar suas possibilidades de cumprir com seus deveres religiosos e morais, suas obr igações familiares ou também seu encontro com Cristo.

A opção de um paciente católico, por exemplo, de não utilizar ou reduzir a dose de medicamentos para a dor, pode ser extremamente angustiante para um profissional de saúde que não partilha da mesma religião ou dos mesmos valores. Na perspectiva de quem cuida, a prescrição de analgésicos pode ser fonte de discordâncias de fundo ético e religioso, quando se trabalha em equipe.

Uma primeira questão é se este tipo de discussão e decisão é partilhada com o paciente ou seus responsáveis. Outro aspecto é se é possível part ilhar esta decisão com a equipe, e em que nível e quais as condições para tal.

Em um continuum de situações relacionadas à dor, a dose do ana 1gésico pode determinar a aceleração do óbito, configurando-se uma situação de eutanásia. Em um histórico da eutanásia para as sociedades ocidentais, Pessini e Barchifontaine (1991) detêm-se no seu significado mais moderno, ou seja, a eutanásia autônoma. Os autores apresentam a situação atual do debate:

Nas épocas precedentes, o paciente ficava sempre em segundo plano. Inicialmente eram outros que decidiam, especialmente os pais e os responsáveis sociais. (...) Agora, a discussão se centra nos direitos dos enfermos a que não se prolongue o sofrimento ou que possam decidir sobre o seu morrer. (pp. 352-353)

A relação entre eutanásia e religião é apresentada por Pessini (1999) a partir do posicionamento do budismo, do islamismo, do judaísmo e do cristianismo.

Para o catolicismo, cujo número de adeptos é maior na América do que na Europa (cerca de 63\% e 41\%, respectivamente, da população de cada continente), a eutanásia é bastante discutida. Pessini (1999) baseia-se em diversos documentos com diretrizes sobre o tema. 
O primeiro é o documento católico mais completo sobre o tema (Declaração sobre a eutanásia), cujo autor destaca passagens sobre a condenação à eutanásia e à distanásia, ou obstinação terapêutica.

Tomando o budismo japonês como exemplo, Pessini (1999) discute as posições desta religião quanto à eutanásia, os transplantes de órgãos e a administração de drogas para o alívio da dor. É uma religião que privilegia a unidade corpo/mente.

Quanto à eutanásia, os bioéticos japoneses exigem o consentimento informado.

Prosseguindo, o autor assinala que o momento da morte é crucial para o budismo, pois é um renascimento. Recomendam "pensamentos salutares" na hora da morte que, no entanto, não deve ser apressada.

$\mathrm{O}$ alívio da dor por meio de drogas deve ser decidido, considerando como preceito primordial a manutenção da consciência na hora da morte. A decisão pessoal deve preceder o suicídio que, embora não seja estimulado, é passível de perdão pelo Buda.

Em nosso país, discutir a humanização da morte pode parecer um paradoxo, considerando a exclusão de grandes segmentos populacionais do acesso à terra e dos benefícios da cultura, da tecnologia e de grupos étnicos de seu ambiente original. No entanto, parece-nos um momento de reflexão importante, considerando a urbanização, o êxodo para as grandes ou médias cidades e a demanda por serviços de saúde.

Como pode ser avaliada a autonomia, no sentido de autodeterminação discutida acima, com os pacientes do sistema de saúde pública? Quais alternativas estão sendo oferecidas a estes pacientes em fim de vida?

O sistema de saúde na França oferece unidades especializadas de cuidados paliativos e a possibilidade de inclusão desta lógica em outros serviços. A formação de especialistas nesta área, sejam os médicos sejam as enfermeiras, atende a uma demanda crescente devida principalmente ao envelhecimento da população. 
Considerações sobre Cuidado Paliativo e Trabalho Hospitalar...

No Brasil, são escassas as unidades de cuidados paliativos. No mosso país, é um tipo de cuidado mais freqüentemente encontrado no atendimento domiciliar, em especial para as classes mais favorecidas economicamente. No que tange aos cuidados paliativos no hospital em que estudamos no Brasil, foi criada, em abril de 2000, uma comissão formada por médicos, enfermeira e fisioterapeuta, a fim de atender ambulatorialmente pacientes que apresentam a dor como sintoma. Em última instância, os pacientes podem ser encaminhados para o Instituto Nacional do Câncer (INCA), com maior volume de recursos materiais.

Propõe-se a atender pacientes portadores de dores agudas ou crônicas - mais de seis meses de duração - associadas a patologias diversas (neuralgia herpética, lombalgias, câncer, AIDS etc.). Embora com dificuldades, tenta articular-se com os atendimentos em ambulatório de saúde mental do hospital. Privilegia o acompanhamento domiciliar a partir de orientações fornecidas à família, no serviço, pelos profisssionais de saúde.

\section{Considerações finais}

Para os pacientes adultos, retomar o trabalho ou o cuidado com os filhos conferem à passagem pelo hospital e à experiência da doença a possibilidade de vivenciarem momentos marcantes, que se integram ou se perdem no cotidiano. Para as pessoas idosas, podem remeter ao medo de não retornarem, de passar no hospital longos períodos ou de aí morrerem. O envelhecimento é um tempo recheado de lembranças e o belo trabalho de Bosi (1994), em Memória e Sociedade: Lembranças de Velhos, resgata a sabedoria de trabalhadores paulistas nesta fase da vida. Para as crianças, a capacidade lúdica de quem cuida delas é muito importante. Em enfermarias de doenças graves, a morte de uma criança pode ser uma das maiores dificuldades enfrentadas por enfermeiras e pessoal auxiliar, assim como pelos médicos (ver, por exemplo, Marguerite \& Schneider, 1999).

As relações familiares e o desejo do paciente serão, em última instância, os principais determinantes da continuidade dos cuidados em um con- 
texto no qual a autonomia das pessoas tenha um valor predominante. Isto requer, em nosso país, que a sociedade se volte a um aprofundamento das interrogações éticas e a um redimensionamento em termos de formação e acompanhamento do trabalho nos hospitais pela sociedade, sem isolar esta discussão do contexto social e político mais amplo.

Nosso foco de discussão não se restringe a um conjunto de direitos do paciente garantidos por lei, mas à possibilidade de construção de um espaço onde a sociedade, os profissionais de saúde e os doutores médicos possam investir, conjuntamente, para uma qualidade de vida melhor - dos pacientes e dos trabalhadores em saúde.

Quanto à formação, em enfermagem, fomos informados, à época da pesquisa, que não havia conteúdo específico durante a graduação (Informação verbal, entrevista com enfermeiras, Brasil, 2000; Loureiro dos Santos, 2001).

Quanto à formação de pessoal auxiliar, pudemos observar, nos depoimentos das entrevistadas, certa irregularidade quanto à inclusão do tema no currículo básico. Foi um dos temas solicitados, durante a pesquisa, para formação complementar em serviço à enfermeira-chefe.

Além desse panorama sucinto do aprendizado formal, baseado no depoimento das participantes da pesquisa, pode-se observar uma ênfase no aspecto técnico da relação com o paciente, em detrimento do relacional, propiciado pela prescrição da organização do trabalho de enfermagem. Horários e ritmos que privilegiam a administração da medicação, os banhos e a verificação de sinais vitais. A interação pessoal com o paciente torna-se um investimento pessoal, configurando a concepção da atividade pelas enfermeiras, técnicas e auxiliares de enfermagem no Brasil.

Para a Ergonomia, a atividade, entendida como ação e linguagem na qual o sujeito exerce sua capacidade de agir e de se comunicar, confere destaque às interações entre os sujeitos do trabalho. As competências construídas coletivamente e o agir cotidiano para uma finalidade comum são explic itados em diferentes metodologias que privilegiam a linguagem. Como assinalam Grosjean e Lacoste (1999), a linguagem é uma ferramenta cada 
Considerações sobre Cuidado Paliativo e Trabalho Hospitalar...

vez mais importante em um trabalho cada vez menos "físico" e cada vez mais "intelectual".

O trabalho relacional realizado pela enfermagem, durante os cuidados em fim de vida, remete a uma dimensão que começa a ter maior espaço, nos estudos sobre o trabalho, com o crescimento do setor de serviços nos países centrais (Cloutier, David, Prevost, \& Teiger, 1998; Falzon \& Lapeyrière, 1998; Gerard, 1998; Leduc, 1997).

A análise da atividade de enfermeiras, em serviços de enfermagem (Cloutier et al., 1998), tem enfatizado a escassez de tempo que as enferme iras e auxiliares dispõem para a interação com o paciente em processo de cura. É predominante a palavra "rápida e útil", na terminologia usada por Grosjean e Lacoste (1999).

A psicopatologia do trabalho (Dejours, 1987) irá tentar desvendar as relações entre o adoecimento do corpo e os mecanismos psíquicos mobilizados pelas situações de trabalho, considerando a ressonância simbólica engendrada no cenário do trabalho e vivenciada pelos trabalhadores. Nesta perspectiva, a organização do trabalho irá produzir impactos no aparelho psíquico do trabalhador.

O medo e a ansiedade são sentimentos identificados no confronto do trabalhador com o mundo da produção, sendo mais difícil, ainda, sua explicitação pela predominância da população masculina neste âmbito. A cooperação, os meios de trabalho e as relações entre os trabalhadores apresentam uma especificidade cuja construção é pouco visível nos coletivos femininos, como é apontado por Hirata e Kergoat (1987). Isto pode ser devido à recente entrada das mulheres em setores organizados pelos homens. Além disso, o trabalho taylorizado, como aponta Carpentier-Roy (1990), não é facilitador de processos identitários nem para os homens nem para as mulheres.

Considerando o sofrimento como inerente à condição humana, Dejours (1993) irá indagar como o sofrimento se transforma em prazer no trabalho, com a noção de sofrimento criativo. Molinier (1995) irá propor uma clínica do trabalho que desvende dispositivos de dominação masculina, em trabalhos realizados por mulheres, como o trabalho de enfermagem. Quest i- 
ona, por exemplo, a idéia de "natureza do trabalho" de enfermagem, cotejando-a com a atribuição histórica às mulheres dos cuidados com os momentos singulares de nascimento e morte humanos.

A relação sofrimento e prazer no trabalho é objeto de reflexão da psicopatologia e, posteriormente, da psicodinâmica do trabalho, formuladas por Dejours. O trabalho seria, então, a função psicológica primordial para o sujeito. Mas que trabalho seria este? Podemos pensar em uma noção ampliada de trabalho. Trabalho emocional, trabalho psíquico? O trabalho remunerado ou, também, o trabalho doméstico, o trabalho filantrópico, voltado para o bem comum?

A importância da ênfase na dimensãorelacional do trabalho de enfermagem tem repercussões, não apenas para a qualidade da assistência aos pacientes e familiares em serviços onde está implicado o cuidado paliativo, como também para a saúde mental das trabalhadoras de enfermagem que lutam por um trabalho significativo e ético, em um contexto de reestruturação e precarização do trabalho.

\section{Agradecimentos}

Agradeço à Profa. Catherine Teiger, pela orientação do estágio na França, no CNAM/Paris; à Profa. Marisa Palácios, pelas discussões e indicações bibliográficas em Bioética e Ética em Pesquisa; à Profa. Katia Sa nches e à Profa. Lenice do Rosário, pela indicação das consultas sobre AIDS no Brasil; ao Prof. Volney Câmara, pela leitura dos originais.

Simoni, M., \& Loureiro dos Santos, M. (2003). Considerations about palliative care and hospital work: a plural approach of the nursing work process. Psicologia USP, 14(2), 169-194.

Abstract: The purpose of this article is to present the authors' effort of synthesizing research material on palliative care as well as the bibliography studied. Firstly, some considerations about palliative care in two 
Considerações sobre Cuidado Paliativo e Trabalho Hospitalar...

structurally different countries, Brazil and France, are presented. The discussion focuses the authors' research experience at a SIDA ward in the first country and at an Intern Medicine ward in the latter, which held cancer and SIDA patients within a palliative care logic. Secondly, aspects related to pain and death are discussed considering concepts of Bioethics alongside the relational dimension concerning health care. The concepts pointed out are those of justice, autonomy, beneficence and non-maleficence. In conclusion, we present some possible contributions of Ergonomics and Work Psychodinamics in the Palliative Care field, taking into special consideration the psychological dimension of this debate.

Index terms: Suffering. Palliative care. Hospitals. Ergonomics. Mental health.

Simoni, M., \& Loureiro dos Santos, M. (2003). Considérations sur le soin palliatif et le travail en hôpital : un abordage pluriel sur le processus de travail d'infirmerie. Psicologia USP, 14(2), 169-194.

Résumé: L'objectif de ce travail est de présenter l'effort de synthèse des auteurs sur le matériel de recherche en soins palliatifs et la bibliographie étudiée. Pour commencer, nous présentons quelques considérations sur le soin palliatif dans deux pays structurellement distincts, le Brésil est la France. La discussion est centrée sur les recherches des auteurs dans un service de SIDA au Brésil et un service de médecine interne en France, qui a adopté la logique des soins palliatifs et a abrité surtout des patients atteints du SIDA ou de cancer. On aborde ensuite les aspects se référant à la douleur et à la mort en considérant les concepts de la Bioéthique et la dimension relationnelle du soin dans la Santé. Les concepts signalés sont ceux de justice, autonomie, bienfaisance et non-malfaisance. On conclut en présentant quelques contributions possibles de l'Ergonomie et de la Psychodynamique du Travail dans le secteur des Soins Palliatifs, considérant spécialement la dimension psychologique de ce débat.

Mots clés: Souffrance. Soins palliatifs. Hôpitaux. Ergonomie. Santé mentale. 


\section{Miguel de Simoni e Mônica Loureiro dos Santos}

\section{Referências}

Ariès, P. (1977). História da morte no ocidente. Rio de Janeiro: Francisco Alves.

Boltanski, L. (1984). As classes sociais e o corpo (2a ed.). Rio de Janeiro: Graal.

Bosi, E. (1994). Memória e sociedade: Lembranças de velhos (3a ed.). São Paulo: Companhia das Letras.

Bulhões, I. (1994). Riscos do trabalho de enfermagem. Rio de Janeiro: Folha Carioca.

Callado, A. (1984). Quarup. Rio de Janeiro: Nova Fronteira.

Carpentier-Roy, M. C. (1990, P semestre). Plaisir et souffrance des infirmières au travail: L'empreinte de l'imaginaire féminin. Revue Prevenir [Travail et Santé Mentale], (2), 23-30.

Cloutier, E., David, H., Prevost, J., \& Teiger, C. (1998, octobre). Santé, sécurité et organisation du travail dans les emplois de soins à domicile. Rapport de recherche. Montréal: IRSST.

Coordenação Nacional de DST e AIDS. (n.d.). 6.0 HIV transmission from mothers to infants in Latin America and the Caribbean. Recuperado em 22 de fevereiro de 2003: www.aids/gov.br/udtv/map_hivtrans.htm

Cosendey, M. (1999). Ecletismo ou subordinação?: Uma análise comparativa das semiologias ocidental contemporânea e tradicional chinesa. Dissertação de mestrado, Instituto de Medicina Social, Universidade Estadual do Rio de Janeiro, Rio de Janeiro.

Damasceno, C. G. (1998). Dimensionamento de efetivos em enfermagem: Contribuições da análise ergonômica do trabalho. Dissertação de mestrado, COPPE, Universidade Federal do Rio de Janeiro, Rio de Janeiro.

De Beir, C. (1994). Formation et accompagnement de fin de vie. UNESCO. Mimeografado.

Dejours, C. (1987). A loucura do trabalho: Estudo de psicopatologia do trabalho (2a ed.). São Paulo: Cortez.

Dejours, C. (1993). Travail, usure mentale (Essai de psychopathologie du travail). Paris: Bayard.

Di Mola, G. (1994). Soins palliatifs en Italie. UNESCO. Mimeografado.

Eloysa, B. (Org.). (1987). I Seminário do Grupo Tortura Nunca Mais. Petrópolis, RJ: Vozes. 


\section{Considerações sobre Cuidado Paliativo e Trabalho Hospitalar...}

Falzon, P., \& Lapeyrière, S. (1998). L'usager et l'opérateur: Ergonomie et relations de service. Le Travail Humain, 61(1), 69-90.

Fortes, P. A .C. (1999, fevereiro). As pesquisas em seres humanos e o princípio ético da justiça. Cadernos de Ética em Pesquisa, 2(2), 22-23.

Freyre, G. (1977). Obra escolhida. Rio de Janeiro: Nova Aguilar.

Freud, S. (1974). Luto e melancolia. In S. Freud, Edição standard brasileira das obras psicológicas completas de Sigmund Freud(Vol. 14, pp. 275-291). Rio de Janeiro: Imago. (Trabalho original publicado em 1917).

Gérard, V. (1998, août). Les relations de service dans des organismes publics: Strategies d'action et de régulation des agents face à l'usager. In Xeme Congrès de l'AIPTLF (pp. 24-27). Bordeaux, França.

Grosjean, M., \& Lacoste, M. (1999). Communication et intelligence collective. Paris: PUF.

Hirata, H., \& Kergoat, D. (1987). Rapports sociaux de sexe et psychopathologie du travail. In C. Dejours (Org.), Plaisir et souffrance au travail (Tome II, pp. 131163). Paris: Editions du CNRS.

Illich, I. (1975). A expropriação da saúde: Nemesis da medicina. Rio de Janeiro: Nova Fronteira.

Lalouette, J. (1995). Funérailles civiles: D'un siècle à l'autre. In N. CzechowsiI \& C. Danziger (Orgs.), Deuils (Série Mutations, n. 128, pp. 190-219). Paris: Autrement.

Leduc, S. (1997). Entre aide et conseil: L'activité d'insertion professionnelle comme relation de service. Mémoire de D.E.A., Université de Picardie Jules Verne, Picardie, França.

Loureiro dos Santos, M. (2001). Cuidado paliativo e organização do trabalho: A concepção na atividade de técnicas e auxiliares de enfermagem. Tese de doutorado, COPPE, Universidade Federal do Rio de Janeiro, Rio de Janeiro.

Mallet, D. (1995). Logique thérapeutique et logique palliative. Connexions, (66), 111117 [L'Evolution des Structures de Soins]. Ramonville Saint-Agne: Erès.

Marguerite, G., \& Schneider, C. (1999, décembre). Le sentiment d'échec en oncologie pédiatrique. Actes des Journées Montpelliéraines de Psychiatrie de l'Enfant et des Professions Associés (pp. 30-31). Montpellier, França.

Masetti, M. (1999). Soluções de palhaços: Transformações na realidade hospitalar. São Paulo: Palas Athena.

Mendes, R. (Org.). (1995). Patologia do trabalho. Rio de Janeiro: Atheneu. 


\section{Miguel de Simoni e Mônica Loureiro dos Santos}

Molinier, P. (1995). Psychodinamique du travail et Identité sexuelle. Thèse du Doctorat en Psychologie, Conservatoire National des Arts et Métiers, Paris.

Morin, E. (1997). O Homem e a morte. Rio de Janeiro: Imago. (Trabalho original publicado em 1970)

Pessini, L. (1999, setembro/outubro). A eutanásia na visão das grandes religiões mundiais (Budismo, Islamismo, Judaísmo e Cristianismo). O Mundo da Saúde, 23(5).

Pessini, L., \& Barchifontaine, C. P. (1991). Problemas atuais de bioética. São Paulo: Loyola.

Raso, G. (1996). Elaboration d'une approche de l'activité soignante dans un service de Médecine Interne. In R. Patesson (Ed.), Intervenir par l'ergonomie, Actes du 31e Congrès de la Sel (Vol. 2, pp. 167-172). Bruxelles, Belgique.

Richard, I. (1996). La mort, l'accompagnement et les soins paliatifs dans un service de médecine interne. Enquète auprès des soignants. Thèse pour le Doctorat en Médecine, Université Paris VII - Denis Diderot, Paris.

Rodrigues, J. C. (1983). Tabu da morte. Rio de Janeiro: Achiamé.

Schrammm, F. R. (1999, Julho). O respeito à autonomia. Cadernos de Ética em Pesquisa, 2(3), 16-19.

Schulze, C. M. N. (1995). As representações sociais de pacientes portadores de câncer. In M. J. Sptiz (Org.), O conhecimento no cotidiano: As representações sociais na perspectiva da psicologia social (pp. 266-279). São Paulo: Brasiliense.

Sontag, S. (1984). A doença como metáfora. Rio de Janeiro: Graal.

Thomas, L. V. (1988). Leçon pour 1'Occident: ritualité du deuil et du chagrin en Afrique noir. In Rituels $d u$ deuil, Travail $d u$ deuil. Nouvelle Revue d'Ethnopsychiatrie. Grenoble: Ed. La Pensée Sauvage, tome 10. (Nouvelle edition: Rituels du deuil, travail du deuil. Ed. Pensée Sauvage, Grenoble, 1995)

Vergara, R. (2001, novembro). Muita dor. Super Interessante, 170.

World Health Organization. (n.d.). Who definition of palliative care. Recuperado em 22 de fevereiro de 2003: http://www.who.int/cancer/palliative/definition/en/

World Health Organization Western Pacific Region. (n.d.). Building Healthy Communities and Populations. Focus 4: Noncommunicable diseases [Overview]. Recuperado em 22 de fevereiro de 2003: http://www.wpro.who.int/themes_focuses/theme2/focus4/themes2_focus4burden.asp 